\title{
Prediction of road traffic noise attenuation due to distance, ground absorption and gradient
}

\author{
H. N. Rajakumara ${ }^{1}$ \& R. M. Mahalinge Gowda ${ }^{2}$ \\ ${ }^{I}$ Department of Civil Engineering, Adhiyamaan College of Engineering, \\ Tamilnadu State, India \\ ${ }^{2}$ P.E.S. College of Engineering, Karnataka State, India
}

\begin{abstract}
The propagation of road traffic noise is also influenced by the ground absorption, distance of source from receiver and road gradient. Hence it is necessary to apply corrections to the measured traffic noise levels. In this study a simple correction model has been developed for ground absorption, the distance and road gradient based on the field data. The method of calculating the ground absorption consists of identifying the locations which are totally or even partially absorbent in nature like backyards with gardens, paddy fields, tree density on either side of the roads and a mixture of absorbent and non-absorbent areas. Field measurements are taken from different locations with a varying percentage of soft ground cover. The correction value for ground absorption is estimated from the difference between the calculated noise levels and measured noise levels at varying percentages of soft ground cover. The correction value for distance is estimated from the difference between the calculated noise levels and measured noise levels at different horizontal and vertical distances over the hard ground surfaces. Similarly, the correction value for road gradient is calculated from the difference between the calculated noise levels and measured noise levels at different road gradients.
\end{abstract}

Keywords: ground absorption, distance, road gradient.

\section{Introduction}

The estimation procedure for noise from road traffic can be usually divided into two parts. The first part is concerned with the evaluation of the source noise level in terms of traffic parameters and the second with the evaluation of the effect of 
the surrounding on the propagation of the noise. If the ground surface between the edge of the near side carriage way of the road segment and the reception point is totally or even partially absorbent in nature ( e.g. grass land, cultivated fields or plantations) an additional correction for ground cover, often referred to as ground absorption correction, must be taken into account [1]. The correction factor is progressive with distance and has a significant impact on reception points nearest to the ground. In open areas the measured traffic noise level in the study area is also influenced by distance between the source and reception point. It can also often produce changes in received noise level of a magnitude similar to those expected from difference in ground cover as mentioned above [2]. For ideal point sources it is inversely proportional to the distance squared, while intensity due to line source is inversely proportional to the distance from the source [3]. Therefore, it is necessary to apply necessary correction to the measured noise levels for distances greater than the reference distance from the centre line of roadway. This correction is often referred to as distance correction. Noise emitted by traffic flow is also influenced by the gradient of the road segment. Generally, gradient cause an increase in traffic noise for upward flows and a decrease in noise for downhill flows [4]. Therefore, a correction should be applied to the predicted values of noise levels when gradient exists.

It is obviously desirable to develop some method which is more sensitive to the distribution of ground cover, distance and gradient, but it is equally important to retain the simplicity of application of the prediction method, in view of the large number of variables which can be introduced, to maintain its usefulness. In this paper a sound attenuation model is developed for distance, ground absorption and gradient of roadway. These models are incorporated in a road traffic simulation model to determine the $L_{e q}$ levels from a steam of vehicles.

\section{Prediction formula}

\subsection{Correction model for distance $\left(\Delta \mathrm{L}_{\mathrm{D}}\right)$}

The basic concept followed in this study to develop the distance correction model is given as follows.

where

$$
\Delta \mathrm{L}_{\mathrm{D}}=\alpha * 10 * \log (\mathrm{Do} / \mathrm{D}),
$$

$\alpha$ is a site parameter whose value depends on site conditions.

$\mathrm{D}$ is the equivalent distance from the road segment to the reception point, $\mathrm{m}$.

$=\sqrt{ }\left(D_{\mathrm{N}} \times D_{\mathrm{F}}\right)$

$D_{N}$ is the perpendicular distance from the receiver to the centerline of the nearest lane, $\mathrm{m}$

$\mathrm{D}_{\mathrm{F}}$ is the perpendicular distance from the receiver to the centerline of the far lane, $\mathrm{m}$.

$\mathrm{D}_{0}=$ Reference distance $=7.5 \mathrm{~m}$

The correction value for distance is estimated from a linear equation of the difference between the calculated noise levels and measured noise levels at 
distances of $10 \mathrm{~m}, 15 \mathrm{~m}, 20 \mathrm{~m}, 30 \mathrm{~m}, 40 \mathrm{~m}, 50 \mathrm{~m}$ and $60 \mathrm{~m}$ from centre line of roadway at the receiver height of $1.2 \mathrm{~m}, 3 \mathrm{~m}, 5 \mathrm{~m}, 7 \mathrm{~m}, 10 \mathrm{~m}$ and $15 \mathrm{~m}$ from the local ground surface. Field measurements are taken from 12 locations in outer ring roads of Bangalore city with varying horizontal and vertical distances. The locations chosen are flat ground with no shielding effect and ground absorption. The relation between the attenuation value of traffic noise and distance at every receiver height is shown in Figure 1. It may be observed that the horizontal distance has more influence on noise attenuation values when the distance is less than $60 \mathrm{~m}$ and it is almost remains uniform when the horizontal distance exceeds $60 \mathrm{~m}$. Further, the height of receiver is also has significant impact on the noise attenuation values (see Figure 2). However, the attenuation values are remains intact with the horizontal distance when the receiver height reaches $15 \mathrm{~m}$.

Based on the attenuation values of traffic noise as a function of horizontal distance and receiver height, the value of site parameter $(\alpha)$ in equation (1) is calculated as follows.

$$
\alpha=\left\{\begin{array}{l}
1.0: \text { if } H_{r} \leq 3 m \\
0.9 *\left(1-H_{r} / 15\right): \text { if } 3 m<H_{r}<15 m \\
0, \text { Otherwise }
\end{array}\right.
$$

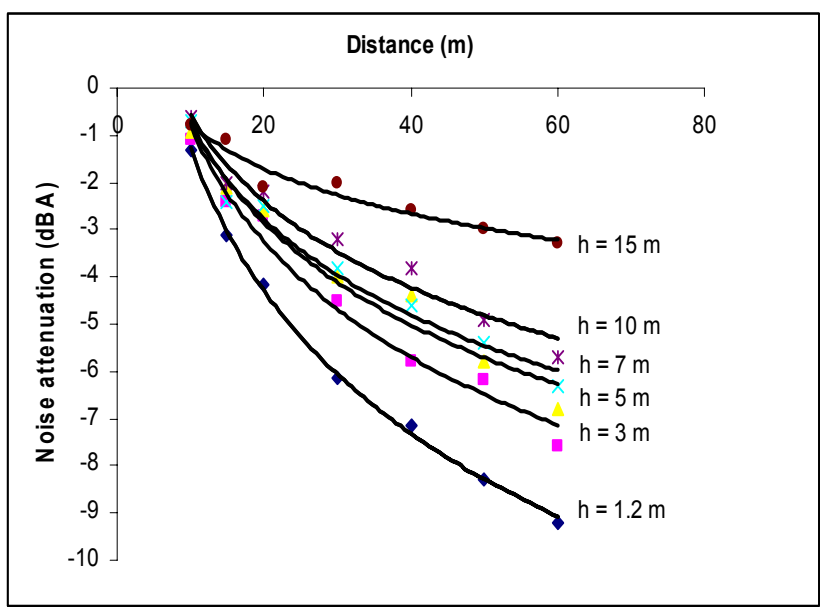

Figure 1: Attenuation of traffic noise as a function of horizontal distance and receiver height when there is no soft ground cover.

\subsection{Correction model for ground absorption $\left(\Delta \mathrm{L}_{\mathrm{GA}}\right)$}

The method of calculating the ground absorption consists of identifying the locations with totally or even partially absorbent in nature, (e.g. grass land, cultivated fields or plantations). In this study, field measurements are taken from 17 locations from in and around Bangalore city with soft ground cover (P) of $25 \%, 50 \%$ and $75 \%$. The locations chosen are backyards with gardens, paddy 
fields, tree density on either side of the roads and mixture of absorbent (grass cover) and non-absorbent areas. The site locations are classified into hard or soft based on the criteria given in FHWA table [1]. All measurements are carried out during normal weather conditions and the effects of wind speed and direction, and temperature stratification are neglected.

The basic concept followed in this study to develop the absorption correction model is given as follows.

$$
\Delta \mathrm{L}_{\mathrm{GA}}=\beta * 10 * \log (\mathrm{Do} / \mathrm{D}),
$$

where $\beta$ is a site parameter whose value depends on site conditions.

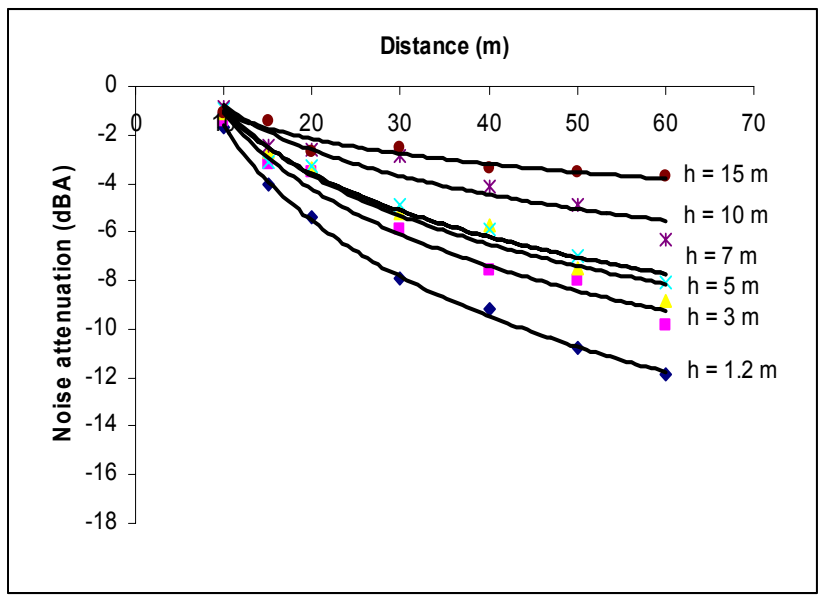

Figure 2: Attenuation of traffic noise as a function of horizontal and receiver height when $\mathrm{P}$ (percentage of soft ground cover) $=25 \%$.

The correction value for ground absorption is estimated from the difference between the calculated noise levels and measured noise levels when soft ground cover is equal to $25 \%, 50 \%$ and $75 \%$ at the receiver height of $1.2 \mathrm{~m}, 3 \mathrm{~m}, 5 \mathrm{~m}, 7$ $\mathrm{m}, 10 \mathrm{~m}, 15 \mathrm{~m}$ and $18 \mathrm{~m}$, and the horizontal distances of $10 \mathrm{~m}, 15 \mathrm{~m}, 20 \mathrm{~m}, 30$ $\mathrm{m}, 40 \mathrm{~m}, 50 \mathrm{~m}$ and $60 \mathrm{~m}$ from centre line of the roadway. The height of source for all types of vehicles is taken as zero. The relation between attenuation value of traffic noise and the percentage of soft ground cover as function of horizontal distance and receiver height is shown in Figure 2 to 4 . According to field measurements, it may be observed that the attenuation of traffic noise due to ground absorption is more when the soft ground cover exceeds 50\%. Further, the ground absorption is also progressive with horizontal distance and receiver height. However, it remains intact when, $H_{r}$ (receiver height), reaches $15 \mathrm{~m}$.

Based on results of the study the value of site parameter $(\beta)$ in the equation (3) is calculated as follows. 


$$
\beta=\left\{\begin{array}{l}
1.0 *(1+P / 100): \text { if } H_{r} \leq 3 m \\
1.2 *(1+P / 100) *\left(1-H_{r} / 15\right): \text { if } 3 m<H_{r}<15 m \\
0, \text { Otherwise }
\end{array}\right.
$$

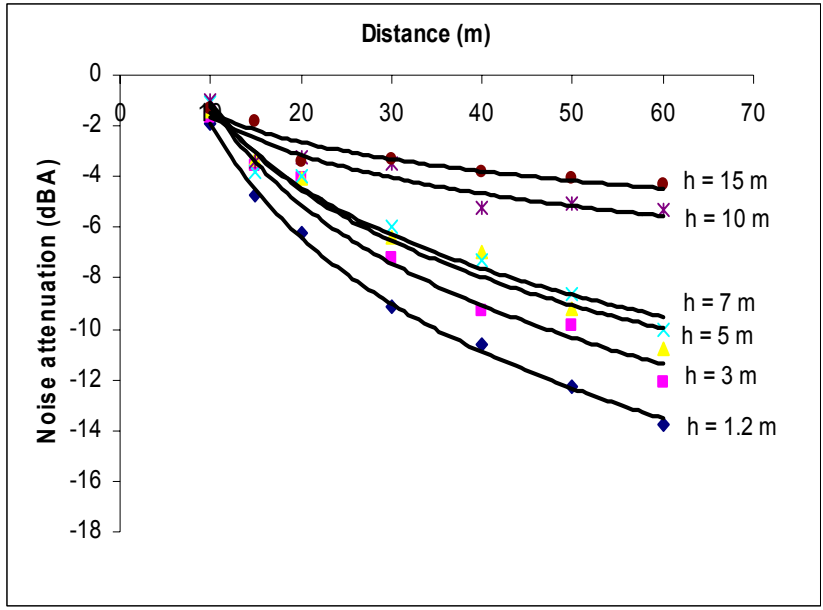

Figure 3: Attenuation of traffic noise as a function of horizontal and receiver height when $\mathrm{P}$ (percentage of soft ground cover) $=50 \%$.

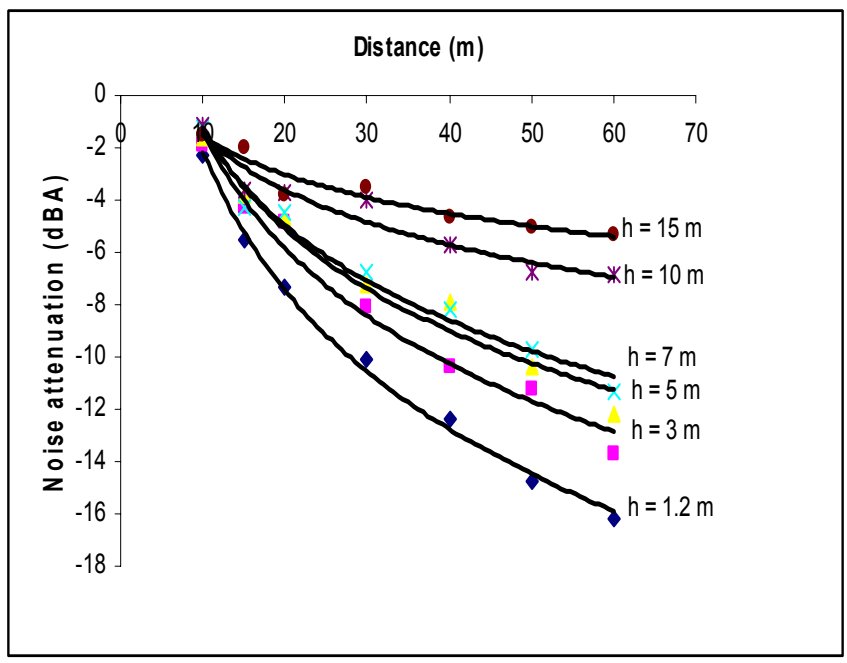

Figure 4: Attenuation of traffic noise as a function of horizontal and receiver height when $\mathrm{P}$ (percentage of soft ground cover) $=75 \%$. 


\subsection{Correction model for road gradient}

Field measurements are performed at 14 locations having different gradients ranging from $1.5-10.5 \%$ on urban road network of Bangalore city, State Highway no.17 and National Highway no.7. The gradient of road surface is measured using Cylone Ghat Tracer. The field study indicated that the gradient above 5\% has significant impact on noise attenuation values.

Based on results of the study and considering the road gradient in terms of percentage gradient, $\mathrm{G}$, the increase in noise due to upward gradients can be expresses as $0.40 \mathrm{G}, 0.38 \mathrm{G}, 0.63 \mathrm{G}, 0.45 \mathrm{G}, 0.42 \mathrm{G}$ and $0.72 \mathrm{G}$ for Two Wheelers, Car/Jeep/Van, Bus, LCV/Minibus, Autorickshaw and Trucks respectively. Similarly, $0.36 \mathrm{G}, 0.32 \mathrm{G}, 0.53 \mathrm{G}, 0.40 \mathrm{G}, 0.38 \mathrm{G}$ and $0.65 \mathrm{G}$ corresponding to decreased noise levels for downhill flow for Two Wheelers, $\mathrm{Car} / \mathrm{Jeep} / \mathrm{Van}, \mathrm{Bus}, \mathrm{LCV} / \mathrm{Minibus}$, Autorickshaw and Trucks respectively. The necessary traffic noise correction model for roadway segments with gradient can takes the following form:

For Uphill flow:

$$
\Delta \mathrm{L}_{\mathrm{UG}}=\frac{\left(0.72 \mathrm{Q}_{\text {Truck }}+0.63 \mathrm{Q}_{\text {Bus }}+0.45 \mathrm{Q}_{\text {Lcv } M \text { B }}+0.42 \mathrm{Q}_{\text {Auto }}+0.40 \mathrm{Q}_{\mathrm{Tw}}+0.38 \mathrm{Q}_{\text {Car/seep } / \text { an }}\right) * \mathrm{G}}{\left(\mathrm{Q}_{\text {Truck }}+\mathrm{Q}_{\text {Bus }}+\mathrm{Q}_{\mathrm{LCV} / \mathrm{MB}}+\mathrm{Q}_{\text {Auto }}+\mathrm{Q}_{\mathrm{TW}}+\mathrm{Q}_{\text {Car/Jep } / \text { an }}\right)}
$$

For Downhill flow:

$$
\Delta \mathrm{L}_{\mathrm{DG}}=\frac{-\left(0.65 \mathrm{Q}_{\text {Truck }}+0.53 \mathrm{Q}_{\text {Bus }}+0.40 \mathrm{Q}_{\text {Lev/MB }}+0.38 \mathrm{Q}_{\text {Auto }}+0.36 \mathrm{Q}_{\mathrm{Tw}}+0.32 \mathrm{Q}_{\text {Car/Jep } / \mathrm{an}}\right) * \mathrm{G}}{\left(\mathrm{Q}_{\text {Truck }}+\mathrm{Q}_{\text {Bus }}+\mathrm{Q}_{\mathrm{LCV} / \mathrm{MB}}+\mathrm{Q}_{\text {Auto }}+\mathrm{Q}_{\mathrm{TW}}+\mathrm{Q}_{\text {Car/Jeep } / \text { an }}\right)}
$$

where

$\Delta \mathrm{L}_{\mathrm{UG}}=$ Correction for Up gradient in dBA.

$\Delta \mathrm{L}_{\mathrm{DG}}=$ Correction for Down gradient in dBA.

\section{Conclusions}

The outdoor propagation of road traffic noise is influenced by many factors. The important ones are ground absorption, the distance between source and receiver and road gradient. In this study a simple attenuation model is developed for ground absorption, the distance between source and receiver and road gradient. The results of the study indicated that the ground absorption is progressive with distance when the percentage of soft ground cover exceeds $50 \%$. Similarly, it may be observed that the horizontal distance has more influence on noise attenuation values when the distance is less than $60 \mathrm{~m}$ from the source and it is almost remains uniform when it exceeds $60 \mathrm{~m}$. Further, the height of receiver is also has significant impact on the noise attenuation values. However, the 
attenuation values are remains intact with the horizontal distance when the receiver height reaches $15 \mathrm{~m}$. The results of road gradient effect indicated that the gradient above $5 \%$ has significant impact on noise attenuation values.

\section{Acknowledgements}

The first author is gratefully acknowledge the financial assistance provided by All India Council for Technical Education, New Delhi, under the scheme Career Award for Young Teachers and the authorities of Adhiyamaan College of Engineering, Hosur, T.N. and P.E.S.College of Engineering, Mandya, Karnataka, for providing necessary facilities and support.

\section{References}

[1] Jain, S.S., Parida, M \& Bhattacharya, C.C., Development of Comprehensive Highway Noise Prediction Model for Indian Conditions. Journal of Indian Road Congress, 62 (3), pp. 453A - 488a, 2001.

[2] Nirjar, R.S, Jain, S.S., Parida, M and Katiyar, V.S., Study of Transport Related Noise Pollution in Delhi. Journal of Institution of Engineers (I), 84, p.6-15, 2003.

[3] Hother Sall, D.C and Chandler Wilde, S.N., Prediction of the Attenuation of Road Traffic Noise with Distance. Journal of Sound and Vibration, 115 (3), pp.459- 72, 1987.

[4] Bengang, Li., Shu - Tao \& Dawson, W., A GIS based Road Traffic Noise Prediction Model. Applied Acoustics, 63(6), pp.679 - 91, 2002

[5] Harris C, M., Handbook of Noise Control; McGraw Hill, USA, 1979.

[6] Yamamoto and Yamashita, M.A., Simple Model for Estimating Excess Attenuation of Road Traffic Noise. Journal of the Acoustical Society of Japan, 8 (1), pp.13 -32, 1987.

[7] LF Cohn and G R Meroy, Environmental Analysis of Transportation Systems, John Wiley \& Sons, New York. 